\title{
Wear of Dental Amalgam
}

J. C. ROBERTS, J. M. POWERS, and R. G. CRAIG, The University of Michigan, School of Dentistry, Ann Arbor, Michigan 48109

\section{Summary}

The wear of dental amalgam was studied by single- and double-pass sliding and by a silicon carbide abrasion test. A dispersed amalgam showed significantly better resistance to two-body abrasion than the spherical amalgams tested. The wear of amalgam was determined by resistance to penetration and by a ductile mode of surface failure over the load range studied. Differences in the wear of amalgam and restorative resins and composites are discussed.

\section{INTRODUCTION}

Single- and double-pass sliding tests along with a two-body abrasion test have been used to characterize the wear behavior of some dental restorative resins and composites. The wear of a commercial unfilled acrylic resin, a commercial composite, and an experimental formulation of an unfilled diacrylate resin under conditions of single- and double-pass sliding was determined by resistance to penetration and the mode of surface deformation. ${ }^{1,2}$ A two-body abrasion test of commercial and experimental restorative resins has shown that addition of a silane coupling agent dramatically improved the wear resistance of the composite. ${ }^{3}$

The purpose of this investigation was to characterize the surface failure of dental amalgam under conditions of single- and double-pass sliding and by a two-body abrasion test.

\section{METHODS AND MATERIALS}

A dispersed amalgam (A), a lathe-cut amalgam (B), and two spherical amalgams [(C) and (D)] were evaluated for mode and extent of surface damage. Product names, batch numbers, manufacturers, and mercury-alloy ratios are listed in Table I.

(C) 1977 by John Wiley \& Sons, Inc. 
TABLE I

Manufacturers and Mercury-Alloy Ratios of Materials

\begin{tabular}{|c|c|c|c|}
\hline Code & Material & Manufacturer & $\begin{array}{l}\text { Mercury- } \\
\text { Alloy } \\
\text { Ratio }\end{array}$ \\
\hline A & $\begin{array}{r}\text { Dispersalloy, } \\
\text { No. A4001 }\end{array}$ & $\begin{array}{c}\text { Johnson \& Johnson, East } \\
\text { Windsor, N.J. 08520 }\end{array}$ & 1.00 \\
\hline $\mathrm{B}$ & $\begin{array}{l}\text { Lathe-cut Alloy, } \\
\text { New True Dentalloy } \\
\text { No. } 3057306\end{array}$ & $\begin{array}{l}\text { S. S. White Dental Products } \\
\text { Div., Philadelphia, Pa. } 10102\end{array}$ & $2^{1.20}$ \\
\hline $\mathrm{C}$ & $\begin{array}{l}\text { Spherical } \\
\text { Spheraloy } \\
\text { Spher-A-Caps } \\
\text { No. } 1028\end{array}$ & $\begin{array}{l}\text { Kerr Sybron Corp., Romulus, } \\
\text { Mich. } 48174\end{array}$ & 0.93 \\
\hline $\mathrm{D}$ & $\begin{array}{l}\text { Caulk Spherical Alloy } \\
\text { Caps } \\
\text { No. } 7478\end{array}$ & $\begin{array}{l}\text { The L. D. Caulk Co., Milford, } \\
\text { Del. } 19963\end{array}$ & 0.85 \\
\hline
\end{tabular}

Cylindrical specimens were prepared by the procedure described in American Dental Association Specification No. $1^{4}$ from approximately $600 \mathrm{mg}$ of amalgam alloy following the manufacturers' recommended mercury-alloy ratios and trituration times. The samples were stored at $37^{\circ} \mathrm{C}$ for 7 days prior to testing. The surface area available for testing was $4 \mathrm{~mm}$ long by $2 \mathrm{~mm}$ wide. The samples were polished to a final finish with $0.05 \mu \mathrm{m}$ legivated alumina (Buehler Ltd. Evanston, Ill. 60204).

The apparatus used to scratch the surface of a specimen and measure the tangential force has been described elsewhere ${ }^{5,6}$ but consisted of a surface grinder, loading jig, diamond slider, friction transducer, and sample holder. A diamond hemisphere $(360 \mu \mathrm{m}$ in diameter) was slid across the surface of the specimens. The sample holder was mounted on the table of a surface grinder moving at a speed of $0.025 \mathrm{~cm} / \mathrm{sec}$.

On one set of samples, the surface failure resulting from single-pass sliding was studied. Tangential force and track width data were collected for each normal load. Double-pass sliding was studied on a second set of samples, in which two, one-transversal scars were superimposed on one another in the same sliding direction. The second 
scar was made for half the length of the first to identify differences between single- and double-pass sliding. For double-pass sliding, only the surface failure classification was studied. In both the single- and double-pass sliding tests, nine parallel scratches that resulted from sliding normal loads of $100-500 \mathrm{~g}$ in increments of $100 \mathrm{~g}$ and $800,1000,1200$, and $1500 \mathrm{~g}$ were made on each material.

The track widths were measured on a metallograph with the use of a calibrated eyepiece. A scanning electron microscope and microprobe were used to further study the wear scars. Statistical analysis of the tangential force data was performed with the use of a computer program for polynomial regression. ${ }^{7}$ Five replications were made for each material and condition.

Two-body abrasion data were obtained on materials A, B, C and a composite resin (E) in previous tests ${ }^{3,8}$ and on material $\mathrm{D}$ in this study. Cylindrical specimens $(4 \mathrm{~mm}$ in diameter and $8 \mathrm{~mm}$ in length) of each material were made in split stainless steel dies after mixing according to the manufacturers' instructions. All specimens were stored at $37^{\circ} \mathrm{C}$ for $24 \mathrm{hr}$ prior to testing.

Each specimen was held stationary in a jig under a normal load of $220 \mathrm{~g}$ (a stress of $0.17 \mathrm{MPa}$ ). Abrasion was caused by a 600 grit silicon carbide paper that was attached to the table of a surface grinder. The table moved at a speed of $0.25 \mathrm{~cm} / \mathrm{sec}$. Each specimen was abraded for a distance of $1.02 \mathrm{~m}$ with each pass of $25.4 \mathrm{~cm}$ made on a fresh abrasive surface. The rubbing surfaces were continually flushed with distilled water to remove wear debris.

Six replications were obtained for each material. Wear was determined by measurement of the change in length of the specimen. The data are reported as volume loss per unit of travel $\left(\mathrm{mm}^{3} / \mathrm{mm}\right)$. Mean values were compared by Scheffe intervals computed from an analysis of variance.

\section{RESULTS}

Average values of tangential force and track width versus normal load are plotted in Figures 1 and 2 for each material (curves A-D, respectively). Curve $\mathrm{E}$ is single-pass data for a composite resin (E). ${ }^{1}$

Polynomial regression curves through zero were fitted to the tangential force versus normal load data. The curves of the amalgams were significantly different from each other and from that of 


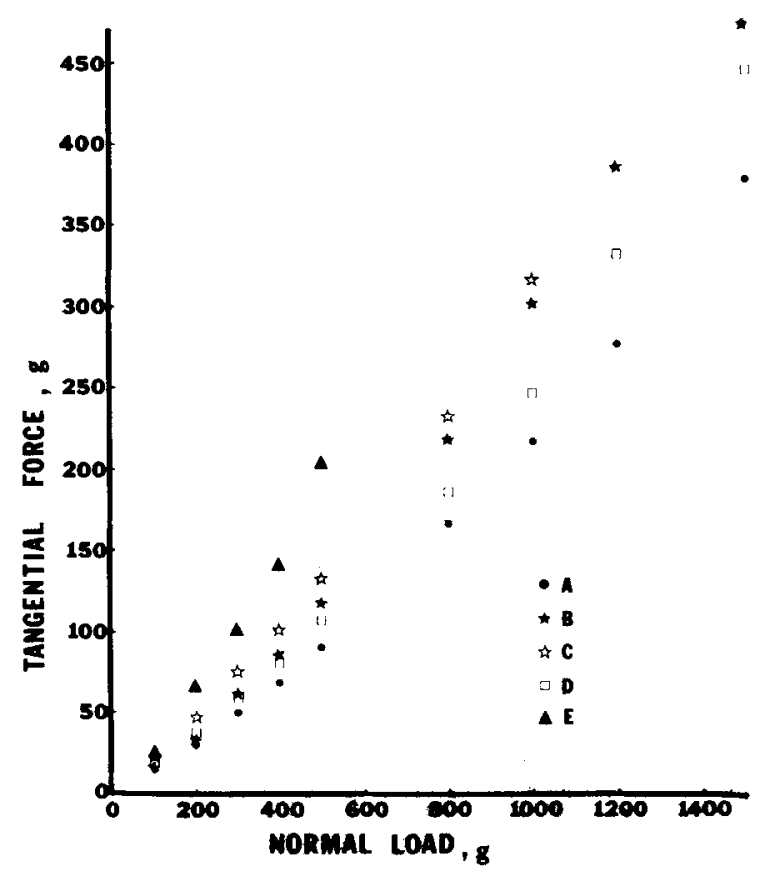

Fig. 1. Tangential force vs. normal load for materials A-E.

\section{TABLE II}

Comparison of Track Width v8. Normal Load for Actual Data and Data Calculated from Elastic Behavior

\begin{tabular}{cccccc}
\hline & \multicolumn{2}{c}{ Measured Behavior } & & \multicolumn{2}{c}{ Elastic Behavior } \\
\cline { 5 - 6 } \cline { 5 - 5 } Material & $\begin{array}{c}\text { Antilog of } \\
\text { Intercept } \\
(1 \mathrm{~g} \text { Load })\end{array}$ & Slope & & $\begin{array}{c}\text { Antilog of } \\
\text { Intercept } \\
(1 \mathrm{~g} \text { Load })\end{array}$ & Slope \\
\hline A & 4.4 & 0.46 & & 6.48 & 0.33 \\
B & 4.4 & 0.48 & & 7.40 & 0.33 \\
C & 5.43 & 0.45 & & 7.51 & 0.33 \\
D & 4.48 & 0.48 & 7.29 & 0.33 \\
E & 5.40 & 0.47 & 9.00 & 0.33 \\
\hline
\end{tabular}




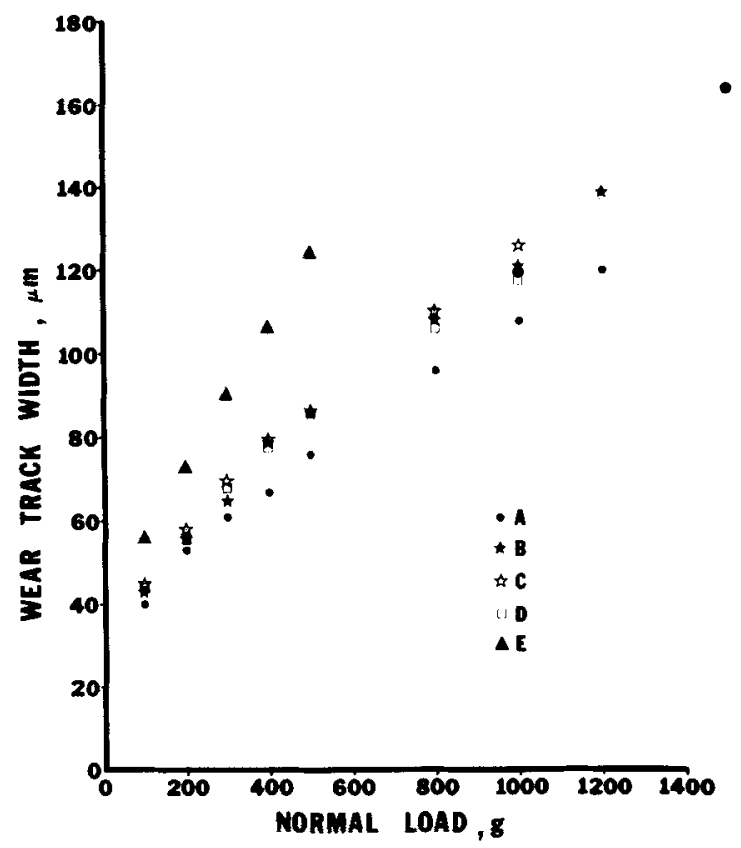

Fig. 2. Track width vs. normal load for materials A-E.

the composite resin (curve $\mathbf{E}$ ). The tangential force versus normal load curve increased most slowly for A, followed by D, B, C, and E.

A linear regression curve was fitted to the log of track width versus $\log$ of normal load data for each material. The slope and antilog of the intercept at a load of $1 \mathrm{~g}$ for each material (A-E) are listed in Table II and compared with values calculated from an equation derived from a special case of Hertz's theory of contact between two elastic spheres.*

* The equation used was:

$$
w=1.82(W R)^{1 / 3}\left[\left\{E_{x}\left(1-\nu_{y}^{2}\right)+E_{y}\left(1-\nu_{x}^{2}\right)\right\} / E_{x} E_{y}\right]^{1 / 3}
$$

where $w$ equals track width, $W$ equals normal load, $R$ equals radius of curvature of diamond sphere, and $\nu$ and $E$ are Poisson's ratio and Young's modulus of amalgam $(x)$ and diamond $(y)$, respectively. Values of $E$ in $\mathrm{GN} / \mathrm{m}^{2}$ and $y$ for materials $A, B, C$, and D were: 36.3 and $0.33,24.1$ and $0.33,23.0$ and 0.33 , and 24.6 and $0.33 . .^{3,10}$ Values of $E$ and $\nu$ for diamond were $930 \mathrm{GN} / \mathrm{m}^{2}$ and 0.33 , respectively. 
The surface failure of all amalgams in the single-pass wear tracks was ductile at normal loads between 100 and $300 \mathrm{~g}$. Above $300 \mathrm{~g}$ the surface failure of materials $A$ through $D$ in the single-pass region was ductile with some wear debris at the edges. This debris was in the form of aggregates of particles with some large flakes. Photomicrographs of single-pass wear tracks for materials A through $\mathrm{D}$ are shown in Figure 3 for a normal load of $800 \mathrm{~g}$. Direction of sliding and a magnification scale are indicated on the figure. Above $1000 \mathrm{~g}$ some small cracks occurred at the outside edge of the wear scar.

The transition from a single- to a double-pass wear scar resulted in no dramatic change in the type of surface failure for materials A through D. For all the amalgams, the surface failure in the doublepass region was ductile with some wear debris at the edge up to a normal load of $800 \mathrm{~g}$. Small cracks, however, occurred at the outside edge of the wear track at normal loads above $800 \mathrm{~g}$.
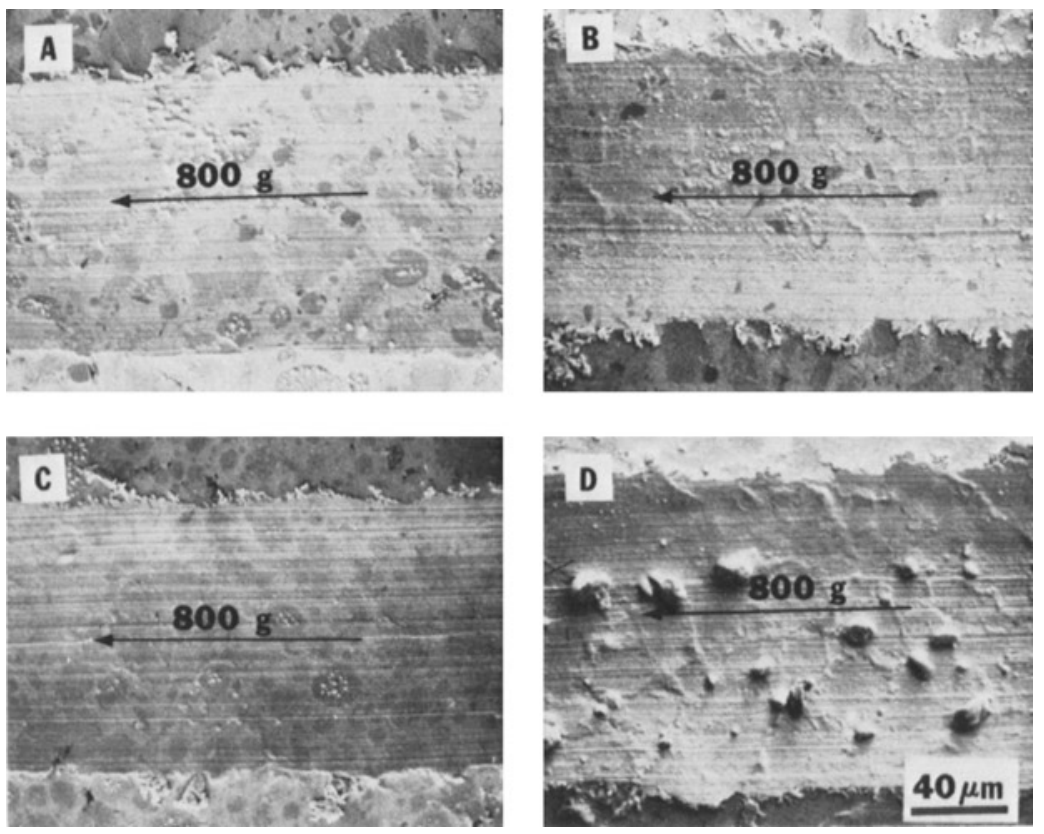

Fig. 3. Scanning electron photomicrographs of wear scars of materials A-D under conditions of single-pass sliding at a normal load of $800 \mathrm{~g}$. 
TABLE III

Comparison of Abrasive Wear of Commercial Amalgams and a Composite ${ }^{\mathrm{a}}$

\begin{tabular}{|c|c|c|c|}
\hline \multirow[b]{2}{*}{ Code } & \multirow[b]{2}{*}{ Materials } & \multicolumn{2}{|c|}{$\begin{array}{c}\text { Wear Rate } \\
\left(\times 10^{-4} \mathrm{~mm}^{3} / \mathrm{mm} \text { of Travel }\right)\end{array}$} \\
\hline & & Mean & $\begin{array}{l}\text { Standard } \\
\text { Deviation }\end{array}$ \\
\hline A & $\begin{array}{l}\text { Dispersed (lathe-cut and spherical) } \\
\text { amalgam }\end{array}$ & 5.60 & 0.29 \\
\hline $\mathrm{B}$ & Lathe-cut amalgam & 6.50 & 0.56 \\
\hline $\mathrm{C}$ & Spherical amalgam & 7.04 & 0.40 \\
\hline $\mathrm{D}$ & Spherical amalgam & 7.43 & 0.47 \\
\hline $\mathbf{E}$ & Diacrylate resin with silanated filler & 7.73 & 0.99 \\
\hline
\end{tabular}

a Mean of six replications. The Scheffe interval was $1.15 \times 10^{-4} \mathrm{~mm}^{3} / \mathrm{mm}$ of travel at the $95 \%$ level of confidence.

Mean values and standard deviations of two-body abrasion data are listed in Table III. The means were significantly different and comparisons of means were made with a Scheffe interval of $1.15 \times 10^{-4}$ $\mathrm{mm}^{3} / \mathrm{mm}$ of travel at the $95 \%$ level of confidence. There were no significant differences between materials $\mathrm{A}$ and $\mathrm{B}$ nor among $\mathrm{B}, \mathrm{C}$, and $\mathrm{D}$ nor among $\mathrm{C}, \mathrm{D}$, and $\mathrm{E}$.

\section{DISCUSSION}

The tangential force is a measure of the force required to deform a material under conditions of single-pass sliding and depends on the penetration of the slider into the material and the mode of deformation. Under the normal loads studied, the amalgam (Dispersalloy) with the lowest values of track width had the lowest values of tangential force. As a group, the amalgams had lower values of track width and tangential force than the composite restorative resin. Both the amalgams and the composite resin deformed nonelastically (Table II).

The mode of surface failure of the amalgams under single-pass sliding remained ductile over the load range studied with no evidence of subsurface failure. In contrast, composites and restorative unfilled resins exhibit a brittle mode of surface failure. The lack of a major change in the mode of surface failure of the amalgams under 
double-pass sliding further indicates the low amount of subsurface failure occurring in the amalgams in contrast to the restorative resins and composites, which show extensive failure by a brittle mode on a subsequent pass (Fig. 4).

Photomicrographs of a microprobe analysis of the wear tracks of materials $A$ and $D$ after single-pass sliding at a normal load of $1500 \mathrm{~g}$ are shown in Figure 5. Evidence of smearing of phases in the wear tracks was observed for both amalgams, but the amalgam of lathe-cut and spherical particles (A) appeared more resistant to this smearing mode of wear than the conventional spherical amalgam (D). In particular, the $\mathrm{Ag}-\mathrm{Cu}$ phase of $\mathrm{A}$ appeared most resistant to the smearing mode of failure. Cracking that did occur at the edges of the wear tracks at normal loads above $1000 \mathrm{~g}$ appeared to propagate around the stronger phases ${ }^{11}$ as shown in Figure 6 for material D.

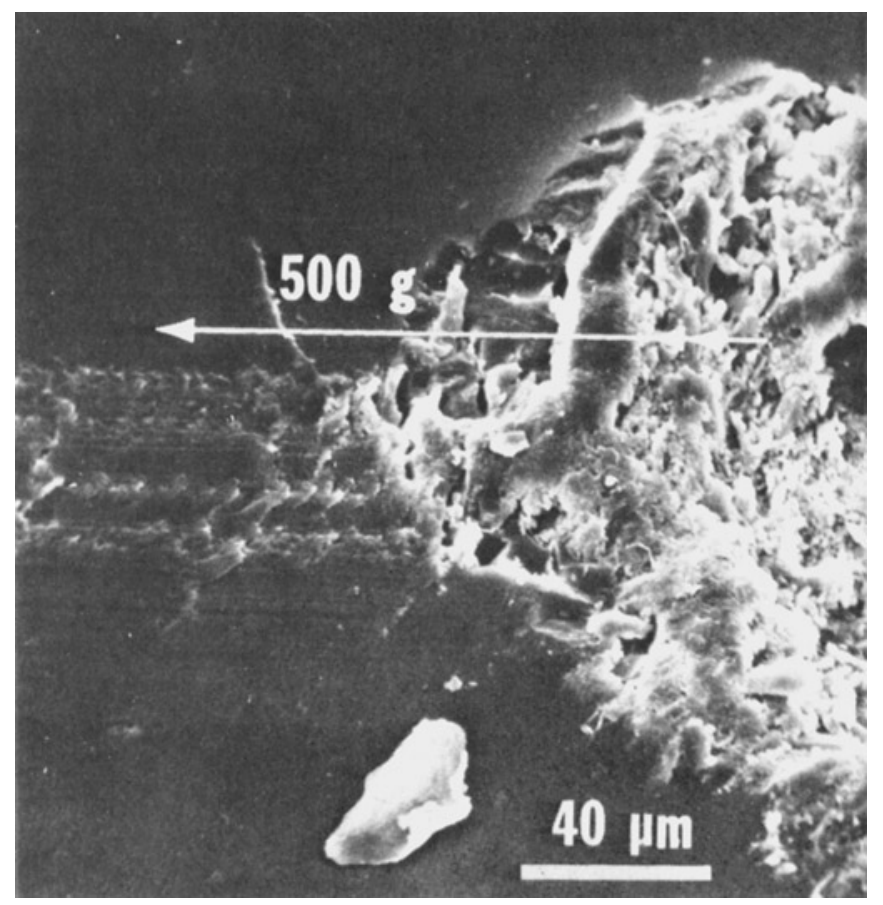

Fig. 4. Scanning electron photomicrograph of the change from double- to single-pass sliding at a normal load of $500 \mathrm{~g}$ for an unfilled diacrylate resin. ${ }^{3}$ 


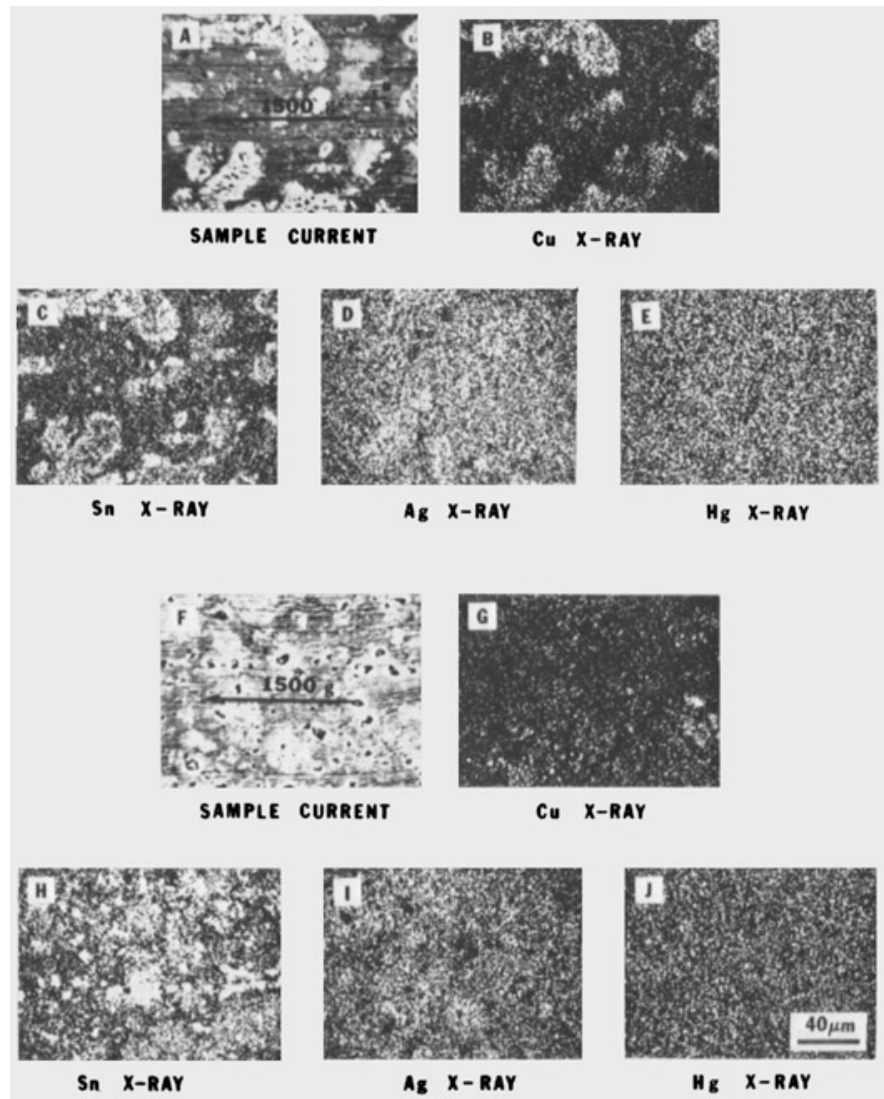

Fig. 5. Microprobe photomicrographs of wear tracks of materials A (A-E) and $\mathrm{D}(\mathrm{F}-\mathrm{J})$, respectively, after single-pass sliding at a normal load of $1500 \mathrm{~g}$.

The wear rate of the dispersed amalgam (A) was lower than that of the spherical amalgams (C and D) and the glass-filled composite resin (E) as measured by two-body abrasion after $24 \mathrm{hr}$. The wear rate of $A$ after 1 month was reduced by $13 \%$ to $4.89 \times 10^{-4} \mathrm{~mm}^{3} / \mathrm{mm}$ of travel by the loss of the Sn-Hg phase $\left(\gamma_{2}\right) .^{8}$ The 1-year clinical data of Leinfelder et al. ${ }^{12}$ partly support the interpretation that the spherical amalgam (C) has a rate of wear comparable to composites with glass reinforcing agents (E) while the dispersed amalgam (A) has a rate of wear comparable to composites with quartz as a filler. 


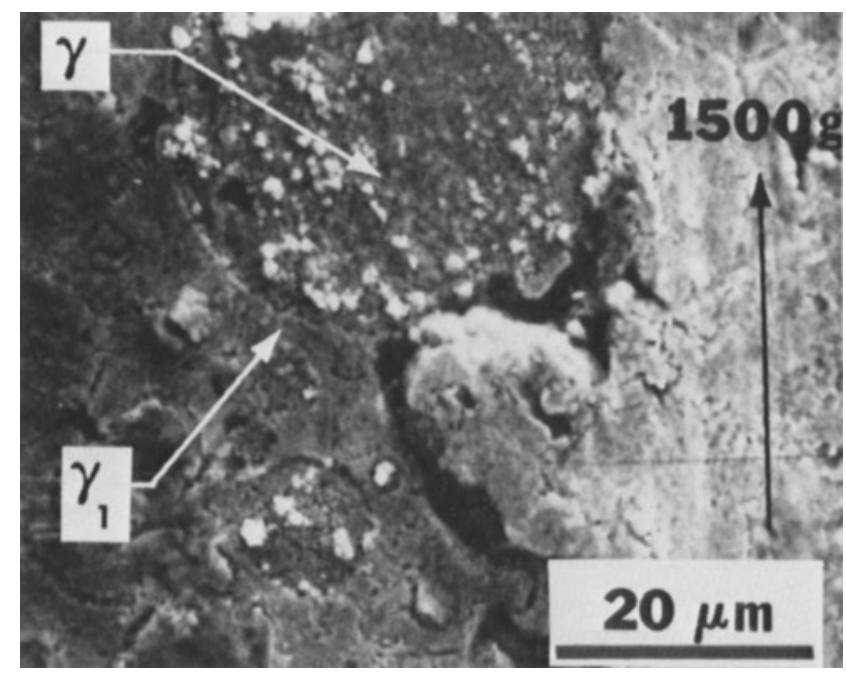

Fig. 6. Scanning electron photomicrograph of crack at outside edge of the wear scar in a single-pass wear track at a normal load of $1500 \mathrm{~g}$.

The silicon carbide abrasion test is able to discriminate between the wear resistance within a variety of composite and unfilled restorative resins ${ }^{3}$ or within amalgams as shown in this study; however, care should be taken in making comparisons between classes of materials such as composites and amalgam until further documentation is obtained of results between these groups.

\section{CONCLUSIONS}

Single- and double-pass wear tests were used to study the surface failure of dental amalgam. The resistance to penetration of the dispersed amalgam under conditions of single-pass sliding was the highest of the materials studied. The wear rate of the dispersed amalgam was lower than that of the spherical amalgams and a composite resin as measured by two-body abrasion. The wear of dental amalgam is determined by resistance to penetration and a ductile mode of surface deformation.

This investigation was supported by USPHS Research Grant DE-03416 from the National Institute of Dental Research, National Institutes of Health, Bethesda, Md. 20014. 


\section{References}

1. J. M. Powers, J. C. Roberts, and R. G. Craig, J. Dent. Res., 55, 432 (1976).

2. J. M. Powers, J. C. Roberts, and R. G. Craig, Wear, 39, 117 (1976).

3. J. M. Powers, L. J. Allen, and R. G. Craig, J. Am. Dent. Assoc., 89, 111 (1974).

4. American Dental Association Guide to Dental Materials and Devices (7th ed.), Chicago, American Dental Association, 1974, p. 297.

5. J. M. Powers and R. G. Craig, J. Dent. Res., 51, 168 (1972).

6. J. M. Powers and R. G. Craig, J. Dent. Res., 51, 605 (1972).

7. University of Michigan Statistical Research Laboratory, A Manual of Elementary Statistics Using MIDAS, Statistical Research Laboratory, Ann Arbor, 1975, p. 301.

8. R. G. Craig and J. M. Powers, Int. Dent. J., 26, 121 (1976).

9. J. M. Powers and J. W. Farah, J. Dent. Res., 54, 902 (1975).

10. D. E. Grenoble and L. J. Katz, J. Biomed. Mater. Res., 5, 489 (1971).

11. K. Asgar and L. Sutfin, J. Dent. Res., 44, 977 (1965).

12. K. F. Leinfelder, T. B. Sluder, C. L. Stockwell, W. D. Strickland, and J. T. Wall, J. Prosthet. Dent., 33, 407 (1975).

Received September 16, 1976 